\title{
Manutenção e Pesquisa e Desenvolvimento (P\&D) como elementos de redução dos custos de produção - um estudo simulado
}

\author{
RESUMO
}

Andreia Maria Berto

andreiaberto@ig.com.br

Universidade Federal de Santa

Catarina (UFSC), Florianópolis,

Santa Catarina, Brasil

\section{Claudelino Martins Dias Junior}

Claudelino.junior@ufsc.br

Universidade Federal de Santa

Catarina (UFSC), Florianópolis,

Santa Catarina, Brasil

\section{Simone Moretto Cesconeto}

s.m.moretto@gmail.com

Universidade Federal de Santa

Catarina (UFSC), Florianópolis,

Santa Catarina, Brasil

\section{Gueibi Peres Souza}

Gueibi.souza@ufsc.br

Universidade Federal de Santa

Catarina (UFSC), Florianópolis,

Santa Catarina, Brasil
Este estudo analisa uma experiência em ambiente simulado do tipo industrial, o período de exercício simulado equivale a 10 (dez) rodadas ou períodos trimestrais de decisões entre 5 (cinco) empresas concorrentes atuando dentro de um mercado fechado (oligopólio). Para tanto, o conjunto de decisões de cada uma das empresas é analisado sobre a perspectiva da administração dos custos de produção, em especial, trata-se do efeito dos montantes de investimentos em manutenção de equipamentos/maquinas e P\&D na redução dos custos com a mão de obra. A metodologia utilizada é predominantemente quantitativa, onde a mensuração da relação presumidamente existente entre investimentos em manutenção de equipamentos e máquinas consorciados a investimentos em P\&D é estimada, valendo-se do conjunto de dados de decisões gerenciais por meio de uma análise econométrica de dados em painel com efeitos fixos. Os resultados das análises sugerem que os investimentos em Manutenção, ceterisparibus, se mostraram tanto mais persistentes, quanto mais intensivos do que os investimentos em P\&D para a amostra analisada.

PALAVRAS-CHAVE: Manutenção. P\&D. Ambiente Simulado. Mão De Obra. Custos De Produção. 


\section{INTRODUÇÃO}

A preocupação gerencial em manter as empresas competitivas acaba por exigir dos seus gestores um comportamento inovador e diferenciado frente a seus concorrentes. A dualidade entre a questão da produtividade e a melhoria dos níveis de qualidade de produto, implica em um comportamento diferenciado em relação a pretensas ações concorrenciais, bem como uma escolha mais assertiva sobre as estratégias possíveis de atuação em dado mercado.

Nesse sentido, o presente estudo estabelece uma discussão acerca da compreensão de conceitos de manutenção em máquinas e equipamentos industriais, bem como o avanço tecnológico de produção, decorrente dos investimentos em $P \& D$ e como estes esforços podem minimizar os custos de produção relacionados à utilização da Mão de obra.

Parte-se do pressuposto de que esses investimentos acarretam uma diminuição dos custos de produção, além de uma melhoria no desempenho operacional, gerando, consequentemente, condições mais favoráveis ao aumento da produtividade como um todo. Neste contexto, este estudo pretende responder ao questionamento de qual a intensidade, a persistência e o sentido da presumida influência entre os investimentos efetuados tanto em Manutenção quanto em P\&D nos custos de Mão de obra dentro de indústrias de manufatura aqui representada por decisões de investimentos de estudantes de pós-graduação em Administração da UFSC.

Porém, há uma discussão recorrente, a decisão de realizar, ou não, atividades de manutenção, mesmo quando sabido de sua importância. Neste sentido, a questão principal é discutir é forma como os custos são analisados. Ou seja, deve-se conhecer os custos de um programa de manutenção, demonstrando-se que o dinheiro aplicado é um investimento e que proporciona uma redução nos custos de reparo e parada de máquinas.

Sendo assim, o presente estudo assume a seguinte hipótese: na medida em que se investe em manutenção de equipamentos/maquinário e P\&D, obtêmse uma diminuição dos custos de produção com Mão de obra.

\section{MANUTENÇÃO E MANUFATURA}

Ao utilizar um equipamento industrial, uma empresa manufatureira deve se preocupar com a utilização racional de seus bens de produção. Essa preocupação se dá em função dos custos envolvidos com a aquisição e a manutenção desses bens, em função de desgastes sofridos em decorrência das condições ambientais e potenciais danos causados pela utilização incorreta.

Os bens de produção ao gerarem produtos, dão existência a novos bens, implicando na existência de consequências ambientais e financeiras. Outro aspecto a ser pensado, diz respeito ao retorno financeiro que os gestores (diretores) precisam obter sobre os investimentos efetuados em bens de produção, dando condições às suas empresas de preservação, reposição e competitividade.

No entanto, a área de manutenção, de uma maneira geral, ainda é carente de ênfase e de atenção por parte de muitos gestores. Por exemplo, um dos fatores que intensificam esse raciocínio, diz respeito à mão de obra utilizada na própria manutenção. Esta mão de obra costuma apresentar baixo grau de 
instrução e, portanto, constitui um impedimento para que se obtenham melhores níveis de desempenho operacional.

Logo, por vezes, equipes de manutenção acabam se caracterizando como simples trocadoras de peças, sem o devido entendimento das causas das falhas existentes nos bens de produção. E com isso, o reflexo se dá no encarecimento do processo produtivo, bem como na mão de obra em si (OTANI; MACHADO, 2008). Para tanto, se faz pertinente uma constante avaliação das políticas de manutenção, antes de buscar-se determinar o plano de manutenção mais adequado ou mesmo a opção de aquisição de novos bens de produção.

Belhot e Campos (1995) explicam que existem sete itens que devem estar presentes na constituição de um plano de manutenção. Sendo eles: compreender a condição efetiva de funcionamento dos bens de produção existentes; identificar os erros e os defeitos mais recorrentes dentro do processo produtivo; determinar um sistema de lubrificação e padronização adequado; instituir um estoque mínimo de peças de troca (reposição) na tentativa de evitar perdas dentro do processo produtivo; compreender as ferramentas necessárias para manutenção e o conserto dos bens de produção; conhecer possíveis mudanças dentro das instalações, produtos e ferramentas, que possam viabilizar uma manutenção mais rápida e efetiva; e analisar possíveis alterações de layout, na tentativa de diminuir o tempo dentro do contexto de produção e manutenção.

Frente a uma economia extremamente globalizada, melhorias incrementais em planos de manutenção, dentro do processo produtivo, implicam em diminuição de custos ou aumento de produção, dependendo do foco dos gestores.

Desta forma, um plano de manutenção deve viabilizar uma combinação de políticas de produção e manutenção, em função dos objetivos de racionalização do tempo e plena utilização dos recursos disponíveis.

A manutenção deve estar atrelada aos objetivos da empresa e ser conduzida de forma a proporcionar um grau de funcionalidade com um custo minimizado. A busca pela qualidade do processo e do produto passa pela qualidade da manutenção, sem a qual o montante investido em sistemas de gestão da qualidade pode ser inteiramente perdido. Apenas uma manutenção adequada pode garantir que o processo não perderá sua capacidade por desvios provocados por problemas no equipamento (SOURIS, 1992).

Dentro desse contexto, diz-se que a manutenção pode ser vista como uma alternativa estratégica dentro das organizações industriais, por ser a responsável direta pela disponibilidade de ativos, tendo reflexos imediatos nos níveis de competitividade dessas empresas. Otani e Machado (2008, p.2) afirmam que "esses resultados serão tanto melhor quanto mais eficaz for a gestão de manutenção".

A ABRAMAN (2003) aponta que, no caso do Brasil, o custo de manutenção por faturamento bruto é de $4,3 \%$ do PIB (Produto Interno Bruto) contra a média mundial de $4,1 \%$, isso significa que, para um PIB (FGV - Fundação Getúlio Vargas) de US\$ 451 bilhões, destes aproximadamente US\$19 bilhões são gastos em manutenção. A mesma ABRAMAM (2007) mostra que é incipiente e escassa a utilização de técnicas mais adequadas à gestão da manutenção e também, de procedimentos que possibilitem melhoras na produção, pois, $41 \%$ das empresas no Brasil não desenvolvem qualquer atividade voltada à manutenção.

Segundo Mirshawa e Olmedo (1993), os custos gerados pela função manutenção são apenas a ponta de um iceberg, onde a ponta visível corresponde 
aos custos com Mão de obra, ferramentas e instrumentos, material aplicado nos reparos, custo com subcontratação e instalação ocupada pela equipe de manutenção. Sob a parte visível do iceberg estão os maiores custos e os invisíveis são representados pela indisponibilidade de equipamento/maquinário.

A relação entre custo de manutenção, custo da indisponibilidade e produtividade foi estudada por Chiu e Huang (1996), apontando que para uma relação custo benefício mais adequada, a manutenção deve ser realizada de forma preventiva, em vez de situações de descontrole do processo produtivo pela falta de manutenção.

Murty e Naikan (1995) demonstram que, a partir do ponto ótimo em investimento com manutenção preventiva, mais investimentos trazem poucos benefícios para a redução dos custos da falha e acabam elevando o custo total. Neste caso, a busca por falha zero, ou seja, $100 \%$ de disponibilidade requer gastos cada vez maiores com manutenção, o que leva à redução do lucro da operação. Encontrar o ponto ótimo de disponibilidade, em que o custo da manutenção proporciona um nível de disponibilidade capaz de gerar máximo lucro à operação, é o grande desafio na gestão da manutenção. A manutenção deve garantir a produtividade e o lucro dos negócios da empresa com o menor custo possível.

Neste contexto, observa-se que a gestão da manutenção tem sido objeto de alguns estudos como, pode-se citar a pesquisa realizada por Jonsson (1997) que buscou analisar o status da gestão da manutenção em empresas de manufatura da Suécia, onde observou que 1/3 das firmas considerava de pouca importância o setor de manutenção, e que isso é um grande obstáculo para proporcionar aprendizagem e trabalhar por melhorias contínuas.

Outro estudo relevante foi a pesquisa sobre o status da gestão da manutenção em empresas de manufatura do Reino Unido realizado por Cholasuke, Bhardwa e Antony (2004), que demonstra o papel crítico que a manutenção assume como suporte das atividades de manufatura e que um aceitável nível de desempenho das indústrias é inalcançável sem o efetivo suporte da gestão da manutenção.

\section{TIPOS DE MANUTENÇÃO}

Existem variações nos modelos de manutenção dos bens de produção dentro dos processos produtivos, mas, é importante ressaltar que nenhuma modalidade substitui outra. O ideal seria a combinação entre as variações existentes e assim, os resultados tendem a ser mais positivos, tendo-se em conta um desempenho geral.

Sennet (2009) acredita que para os componentes com características simples de reposição há um estreitamento entre o modelo ideal de ações preventivas e corretivas, em função do nível de detalhamento fornecido pelos fabricantes, assim obtém-se uma manutenção com menor custo e mais precisa. Esse cenário ideal, dificilmente ocorre quando se trata de componentes que necessitam de reposição complexa, que neste caso apresentam uma manutenção mais cara e probabilística.

\section{Manutenção Corretiva}

Dentre as manutenções existentes, esta é mais primária dentre os 
modelos de manutenção. Ocorre para reparar algo após uma avaria, ou na incidência de desempenho inferior ao esperado. Segundo Xavier (2005), a manutenção corretiva pode ser subdividida em:

- Manutenção corretiva não planejada: esse tipo de manutenção funciona com a correção de falhas aleatórias, isto quer dizer que fará o ajuste de uma falha específica ou na ocorrência de desempenho inferior após a ocorrência do fato. Esse molde de manutenção acarreta altos custos, isto porque há perda de produção, bem como prejuízos aos bens de produção, que é o reflexo mais evidente. Belmonte e Scandelari (2006) lembram que, o simples planejamento e utilização do bom senso podem aperfeiçoar manutenções futuras, reduzindo-as ao máximo e diminuindo os gastos com tais operações. Muitas das manutenções corretivas não planejadas ocorrem devido ao fato da não preocupação dos funcionários quanto ao controle de equipamentos, sendo que a operação advinda da rotatividade de funcionários nos diferentes postos de trabalho e variados horários são as características principais para tal manutenção;

- Manutenção corretiva planejada: essa prática ocorre na medida em que há um acompanhamento e uma revisão dos bens de produção. Eventualmente, pode acontecer quando os gestores optem por operar as máquinas até que ocorra uma falha, tendo-se em conta que ao se planejar o processo de manutenção, este poderá apresentar-se mais barato, seguro e ágil.

\section{Manutenção Preventiva}

Nesse modelo o que se pretende é a redução de falhas ou a diminuição do desempenho operacional, sempre considerando um planejamento que está baseado em períodos estabelecidos de tempo. Xavier (2005) diz que a prevenção mais adequada é aquela que trabalha com a determinação adequada de períodos de tempo. Todavia, em função do perfil mais conservador dos gestores, os intervalos estipulados costumam ser menores do que o necessário, e com isso ocorrem mais paradas de produção e, consequentemente, trocas desnecessárias de peças.

Murty e Naikan (1995), por sua vez, demonstraram matematicamente que, há retornos positivos na relação custo benefício entre custos de manutenção e diminuição de custos de produção voltados à Mão de obra, porém alertam que, a partir do ponto ótimo em investimento com manutenção preventiva, mais investimentos trazem poucos benefícios para a redução dos custos da falha e acabam elevando o custo total. A busca por falha zero requer gastos cada vez maiores com manutenção, o que leva à redução do lucro da operação. Para tanto, é necessário encontrar o ponto ótimo de disponibilidade, em que o custo da manutenção proporciona um nível de disponibilidade capaz de garantir a produtividade e o lucro dos negócios da empresa com o menor custo possível.

\section{Manutenção preditiva}

Diz-se como manutenção preditiva aquela que trabalha com um conjunto de atividades de acompanhamento dos indicadores ou parâmetros relacionados ao desempenho dos bens de produção. Isso sempre de maneira contínua e sistemática, assim é possível identificar se há ou não a necessidade de intervenção dos bens de produção. 
Mirshawka (1991) e aponta como maiores benefícios a previsão de falhas com antecedência suficiente para que os equipamentos sejam desativados em segurança, reduzindo os riscos de acidentes e interrupções do sistema produtivo; redução de prazos e custos de manutenção pelo conhecimento antecipado das falhas a serem reparadas; melhoria nas condições de operação dos equipamentos devido a menor desgaste, maior rendimento e produtividade. Esse tipo de manutenção é conhecida também como CBM - Condition Based Maintence - ou seja, Manutenção Baseada na Condição. Esse molde possibilita um tempo maior de funcionamento dos bens de produção e a interferência só ocorre a partir da análise de dados e não de forma aleatória (XAVIER, 2005).

\section{Manutenção Detectiva}

Para Xavier (2005) ao se tratar de manutenção detectiva, fala-se de atividades em cima de sistemas de proteção ou comando. Ou seja, busca-se identificar falhas não perceptíveis, que ficam ocultas, mas que implicam negativamente no processo produtivo. Portanto, ao lançar mão de sistemas automatizados para as operações, os gestores aumentam a confiabilidade das operações e reduzem os erros e as perdas.

De toda forma, como apontam Otani e Machado (2008), o mais relevante é perceber que, entre todos os tipos de manutenção nenhuma modalidade substitui outra, porém associadas uma da outra, trarão resultados positivos em termos de performances gerais nas gestões das empresas.

Adiante, discute-se o impacto dos investimentos de P\&D na indústria.

\section{P\&D NA INDÚSTRIA}

No atual quadro econômico em que as empresas se instalam, delimitado por alta competitividade, qualidade dos produtos e concorrência pesada, o êxito empresarial está cada dia mais atrelado à capacidade de inovação tecnológica, colocando novos produtos no mercado, com custo benefício maior para o cliente, melhor qualidade e em velocidade maior do que dos concorrentes.

Neste cenário, observa-se que P\&D, a mais clássica das atividades "inovativas", assume, juntamente com atividades de manutenção industrial, papeis de destaque, influenciando diretamente o processo de inovação das empresas e dominando o estado da arte das novas tecnologias (ANDREASSI; SBRAGIA, 2002).

Assim, fazer ou não fazer P\&D deixou de ser uma opção para a totalidade das empresas, pois, a cultura de inovar já estava institucionalizada e sem chance de reversão. Cabe as empresas inovar da forma certa, em produtos certos, em momentos oportunos e a custo reduzido, ou seja, uma questão de organização (CHRISTENSEN, 2002).

Como consequência deste contexto, verifica-se aporte representativo de investimento em P\&D na medida em que possibilita dar aporte a transformação do conhecimento incorporado pela empresa na sua linha de produtos para satisfazer as necessidades dos clientes atuais ou gerarem novas necessidades (MORT, 2001). Para Langlois (2003), a área de P\&D é uma das fontes mais avultadas para a geração do conhecimento e, portanto, representa o repositório do recurso competitivo de valor agregado mais relevante, oferecendo a condição 
ímpar de diferenciação.

Esta ampliação da função de P\&D dentro do ambiente das empresas reafirma sua importância para a inovação, não apenas de produtos, mas, de processos operacionais e gestão. Esta relevância se reflete, também, nas empresas pelos acréscimos significativos do uso de recursos e pela autonomia na sua alocação (GOEL, 1999).

O impacto destas alternativas se reflete diretamente na gestão de custos, notadamente na possibilidade de flexibilização e vinculação do montante total de custos fixos à receita gerada.

Os custos fixos são constituídos essencialmente por salários mensais, definidos com base no vínculo trabalhista, das equipes de técnicos e de pesquisadores, quando da adoção do modelo de realização interna das atividades de P\&D. Ao optar pela externalização das atividades de pesquisa a empresa poderá se beneficiar, da redução de valores de despesas financeiras em virtude da não obrigatoriedade de acompanhar a evolução tecnológica, em termos de bens de capital destinados à pesquisa, deixando de imobilizar seu capital para esta finalidade (MORRISON, 2002). Porém, poderá representar um risco ao negócio, quando da disponibilização do conhecimento que a empresa necessitará dispor a terceiros (WILLIAMSON, 1996).

Campos e Valadares (1999) ressaltam que a inovação tecnológica é a grande ferramenta para o crescimento econômico, para os ganhos de eficiência e de competitividade. Calmanovici (2011) e Queiroz (2011) afirmam que empresas inovadoras que trabalham com investimentos constantes em $P \& D$ e que mantém ferramentas de prospecção e avaliação de novas oportunidades conseguem ganhos mais eficazes com a inovação, são mais competitivas e contribuem para a economia, fortalecendo o esforço nacional no campo da ciência e tecnologia.

Complementarmente, Hulten (2000) reafirma a importância do investimento em P\&D, apontando que a análise do crescimento econômico é dada pela divisão em duas partes, a formação de capital e a tecnologia. Indo de encontro com o que os teóricos da nova teoria do crescimento e para um ramo da economia neoclássica, que o aumento da produtividade é dado por investimentos em capital humano, conhecimento e capital fixo. Por outro lado, comenta que o mecanismo por meio do qual a inovação atua não é de fácil compreensão, pois, há heterogeneidade entre as empresas, além de dificuldade em garantir o retorno financeiro do processo de inovação.

Chaney et al (1991), defendendo a importância da inovação para as empresas, lembram que muitas análises empíricas têm demonstrado a relação entre indicadores relacionados à inovação, tais como gastos com P\&D, e o desempenho das empresas.

Hall (1987) em sua pesquisa com empresas americanas públicas do setor de manufatura relacionou os indicadores de gastos com P\&D e investimentos de capital com a taxa de crescimento. Os resultados mostraram que as empresas que não possuem de P\&D cresceram, em média, 1 a $2 \%$ menos do que as empresas que possuem esses programas, bem como, identificou que o investimento em P\&D é duas vezes mais eficiente do que o investimento de capital ao seu efeito na taxa de crescimento.

É oportuno observar que Andreassi (1999) em estudo sobre vários setores da economia brasileira rejeitou a hipótese de existência de uma relação significativa entre despesas de P\&D em período precedente e lucratividade em períodos subsequentes. A hipótese de relação entre a despesa em P\&D em 
período precedente e o crescimento do faturamento em período posterior, com um intervalo de dois anos, pode ser aceita para alguns segmentos com restrições, pois, não obteve resultados significativos quando da análise dos setores industriais contidos na amostra.

Dando continuidade a proposição de avaliar o impacto dos investimentos em manutenção e $P \& D$ nos custos de produção descrevem-se os procedimentos metodológicos a seguir.

\section{PROCEDIMENTOS METODOLÓGICOS}

Este estudo é enquadrado como uma pesquisa de abordagem quantitativa. Quanto aos objetivos define-se como descritiva explicativa, procurando descrever as razões pelas quais o comportamento de algumas variáveis no ambiente simulado em estudo. Para tanto, sua finalidade está vinculada ao desenvolvimento de uma hipótese e da aproximação entre o pesquisador e a realidade estudada, ampliando as condições de interpretação e compreensão do fenômeno e do esclarecimento de conceitos (LAKATOS; MARCONI, 1996).

Em tais condições possibilita-se a ponderação de indicadores com características específicas evidenciadas dentro de uma população e, portanto, a compreensão de quais são as relações de dependências entre as variáveis em análise. Buscou-se compreender o quanto o montante de investimentos em manutenção e P\&D podem afetar custos de produção, em especial, custos associados à mão de obra direta.

A delimitação do universo de pesquisa é dada pela participação de 5 (cinco) alunos de pós-graduação em níveis de mestrado e doutorado, no primeiro semestre de 2015. Os dados analisados foram retirados do conjunto de decisões individuais de cada uma das empresas simuladas e os resultados obtidos equivalem a aproximadamente 3 (três) anos de gestão empresarial ou 10 (dez) trimestres de decisões.

Inicialmente, para o exercício de simulação em análise, a capacidade de produção instalada foi de 400.000 (quatrocentas mil) unidades para todas as empresas. De acordo com seu nível de competitividade em gerar receitas, as empresas assumiam total liberdade de aumento dessa capacidade, tendo em conta que o investimento preliminar era de $\$ 20$, para cada unidade a mais a ser produzida. Ademais, de acordo com o regramento da simulação nada era observado sobre uma política de investimentos em Manutenção.

Outras formas possíveis de aumento da capacidade instalada, inerente às regras de simulação inicialmente expostas, seriam a utilização de horas extras até o limite de $25 \%$ da capacidade de produção instalada para o momento, com os devidos custos adicionais ( $50 \%$ sobre o custo de mão de obra) ou ainda a decisão, por maioria simples das concorrentes, de que a capacidade instalada de apenas 1 (um) turno de produção (8 horas trabalhadas) fosse dobrada, o que efetivamente ocorreu a partir do $8^{\circ}$ trimestre.

No entanto, o mesmo regramento sugeria que metade do montante dos investimentos em P\&D dinamizariam os processos de trabalho, sendo assim um fator importante na redução dos custos de produção. Portanto, as contribuições desses investimentos estiveram sempre associadas com os investimentos em Manutenção segundo o regramento da simulação na análise dos custos de produção em todo ciclo de gestão da manufatura. 
O ferramental estatístico utilizado para a discussão dos resultados e verificação da hipótese de pesquisa foi uma análise econométrica de dados em painel com a estimação de modelos com efeitos fixos, tendo-se em conta a relação existente entre as variáveis de investimentos em Manutenção, P\&D em relação aos Custos de Mão de obra. Neste sentido, os dados utilizados foram coletados após o término do exercício de decisões, contendo a amostra analisada 50 (cinquenta) observações e sendo gerados 3 (seis) modelos discutidos a seguir.

Definidos os procedimentos metodológicos analisam-se o conjunto de dados fornecidos pelo ambiente de simulação.

\section{ANÁLISE E DISCUSSÃO DOS RESULTADOS}

De acordo com a metodologia exposta foram estimados três modelos loglog (cuja interpretação dos parâmetros estimados se dá em termos de elasticidades), tendo em vista uma exploração mais ampla e a tentativa de mensuração a possível da influência dos investimentos em Manutenção e P\&D no Custo de Mão de obra. Deste modo, apresenta-se o modelo do custo de Mão de obra em função da Manutenção defasada (Tabela 1), o modelo do custo de Mão de obra em função do P\&D defasado (Tabela 2) e, finalmente, o custo da Mão de obra em função da Manutenção e do P\&D defasados (Tabela 3).

Tabela 1 - Custo de Mão de obra em função da Manutenção defasada

\begin{tabular}{ccccc} 
Const & Coeficiente & Erro Padrão & razão-t & p-valor \\
I_Manutenção_1 & 4,88088 & 0,728296 & 6,7018 & 0,0011 \\
I_Manutenção_2 & 0,0962518 & 0,0150909 & $-6,3781$ & 0,0014 \\
I_Manutenção_3 & $-0,0977991$ & 0,0247872 & $-3,9455$ & 0,0109 \\
I_Manutenção_6 & $-0,109876$ & 0,046252 & $-2,3756$ & 0,0635 \\
I_Manutenção_7 & $-0,162661$ & 0,0313245 & $-5,1928$ & 0,0035 \\
\hline
\end{tabular}

Fonte: Autoria própria. Adaptado de Software aplicativo GRETL (2016).

Como pode ser visualizado na Tabela 1, em linhas gerais o custo da Mão de obra foi reduzido, quando ocorrem aumentos nos investimentos em manutenção. Destaca-se que pode ser dado em função da não-significância para o comportamento dos custos e o aumento de investimentos em manutenção no mesmo período de tempo, sendo assim a maior intensidade da relação se mostrou presente na maior defasagem possível, a sétima. O parâmetro estimado indica que a cada $1 \%$ que é acrescido no montante de investimento em manutenção no trimestre atual se reflete em uma redução no custo de Mão de obra em aproximadamente $0,16 \%$ sete trimestres mais tarde, enquanto que o aumento realizado apenas em um trimestre atrás se reflete em aproximadamente $0,1 \%$ na redução dos custos com Mão de obra. Estes resultados sugerem a existência não apenas de uma relação em sentido inversa dessas variáveis, mas que esta relação é relativamente persistente no tempo.

Tais resultados se mostram mais interessantes quando comparados aos resultados estimados para a influência dos investimentos de P\&D no custo de Mão de obra. Observa-se em Tabela 2, que os aumentos de investimento realizados em P\&D no trimestre atual, se mostram como um fator de elevação do Custo de Mão de obra, estabelecendo uma relação direta que se reverte na medida em que o tempo passa e este investimento aparentemente revela sua 
maturidade. Isto pode ser ilustrado a partir da comparação do parâmetro estimado para a sétima defasagem, onde um aumento de $1 \%$ nos investimentos em P\&D parece acarretar uma redução de $0,13 \%$ no custo de Mão de obra sete trimestres mais tarde, enquanto que o acréscimo de $1 \%$ neste mesmo tipo de investimento corrobora para aumentar o custo da Mão de obra em 3,17\%, revelando que este aumento, ao menos na quantidade de defasagens que os graus de liberdade permitiram estimar, não se apresenta diluído.

Tabela 2 - Custo de Mão de obra em função do P\&D defasado

\begin{tabular}{ccccc} 
& Coeficiente & Erro Padrão & razão-t & p-valor \\
Const & 3,1799 & 0,442765 & 7,1819 & 0,0004 \\
I_PD & 0,0411652 & 0,0191161 & 2,1534 & 0,0748 \\
I_PD_1 & $-0,0945811$ & 0,0201126 & $-4,7026$ & 0,0033 \\
I_PD_3 & $-0,0399412$ & 0,0125279 & $-3,1882$ & 0,0189 \\
I_PD_7 & $-0,138443$ & 0,0401299 & $-3,4499$ & 0,0136 \\
\hline
\end{tabular}

Fonte: Autoria própria. Adaptado de Software aplicativo GRETL (2016).

Outro ponto que merece destaque nesta comparação entre a influência dos investimentos em manutenção e os investimentos em P\&D no custo de Mão de obra remete a quantidade de defasagens que se mostraram estatisticamente significantes. Enquanto que os investimentos em manutenção apresentaram cinco defasagens como significantes, os investimentos em P\&D revelaram apenas três. Estes resultados sugerem a possível necessidade de mais tempo para maturação dos investimentos em P\&D do que em manutenção para possíveis reduções no custo de Mão de obra, o que revela a necessidade de mais pesquisa com amostras maiores, para que esta hipótese possa ser de fato testada.

No entanto, é evidente que uma maior robustez e fidedignidade destes parâmetros podem ser obtidas em ambas variáveis de forma conjunta. Para tanto, em um mesmo modelo, na medida em que é plausível assumir que a influência de aumentos de investimentos em P\&D ou manutenção apresentam sua influência no custo de Mão de obra modificada pelo comportamento do outro. Portanto, a influência de elevações de investimento em manutenção no custo da Mão de obra é modificada dada a existência de elevações nos investimentos em P\&D e viceversa. Para tanto, foi estimado um modelo com ambas as variáveis do lado direito da equação (ver Tabela 3).

Tabela 3 - Custo de Mão de obra em função da Manutenção e do P\&D defasados

\begin{tabular}{ccccc} 
Const & Coeficiente & Erro Padrão & razão-t & p-valor \\
I_Manutenção & 1,96078 & 0,151176 & 12,9702 & $<0,0001$ \\
I_Manutenção_1 & $-0,0678638$ & 0,010398 & $-6,5266$ & 0,0002 \\
I_Manutenção_2 & 0,0870877 & 0,0104903 & $-8,3017$ & $<0,0001$ \\
I_Manutenção_5 & $-0,0592081$ & 0,0110884 & 5,3396 & 0,0007 \\
I_PD_1 & $-0,0338927$ & 0,00277677 & $-12,2058$ & $<0,0001$ \\
I_PD_3 & 0,00815697 & 0,00415829 & 1,9616 & 0,0854 \\
I_PD_6 & 0,0461487 & 0,0170043 & 2,7140 & 0,0265 \\
\hline
\end{tabular}

Fonte: Autoria própria. Adaptado de Software aplicativo GRETL (2016).

Como pode ser observado na Tabela 3, os resultados se mostraram um tanto quanto contraditórios quando comparados com os modelos das Tabelas 1 e 2 . Fato este que revela o caráter não-conclusivo da estimativa das influências quando analisadas de forma conjunta e a necessidade da realização de mais 
pesquisa neste tema. Um fato que possivelmente se mostrou influente neste resultado foi a impossibilidade de se considerar ao menos o mesmo número de defasagens do que as realizadas nas análises ceteris-paribus (individuais), dado o reduzido número dos graus de liberdade. Sendo assim, estimativas com amostras maiores se mostram necessárias para que se possa compreender melhor a influência conjunta de ambos os investimentos no custo de Mão de obra.

\section{CONSIDERAÇÕES FINAIS E CONCLUSÕES}

Todo e qualquer plano de Manutenção é entendido como fundamental para as empresas manufatureiras, considerando que este venha a contribuir para o aumento da competitividade empresarial. Não obstante, cabe mencionar que não necessariamente todos os investimentos em manutenção estão vinculados à redução dos custos de produção, talvez o retorno para esse tipo de investimento observa-se por meio de outros indicadores, como: o incremento da produtividade, a minimização dos tempos de setup e a redução do número de falhas.

A amostra em análise centra-se em verificar se a hipótese de que os investimentos em manutenção de equipamentos e máquinas consorciados aos investimentos em P\&D contribuem para a redução dos custos de produção com Mão de obra. Desta forma, dada a verificação de 10 (dez) séries temporais de investimentos em Manutenção por parte de empresas simuladas concorrentes, observa-se que o padrão de comportamento do ambiente leva em consideração o que o universo teórico traz como orientação primeira, ou seja, a ideia de que a existência de um plano de manutenção, pode efetivamente contribuir para a redução dos custos associados à produção, neste caso para o custo de Mão de obra.

No entanto, não se pode afirmar de que as decisões de investimentos tinham por base um plano de manutenção bem formatado, além do que desconheciam a repercussão de que esses investimentos teriam ao longo do tempo (nos trimestres subsequentes). Assim, para aqueles que optaram pelos investimentos em Manutenção observa que puderam contar com a repercussão deles em pelo menos dois períodos ou trimestres consecutivos e que esses investimentos tem uma repercussão mais imediata (curto prazo, neste caso, no mesmo trimestre) do que os investimentos em P\&D, os quais se atrelam a retornos de médios e longos prazos (segundo e terceiro trimestres posteriores).

Quando analisados de forma individual, ou seja, ceteris-paribus, os investimentos em manutenção se mostraram mais intensos e persistentes na redução dos custos de Mão de obra. Assim, a estimativa de ambas as variáveis (Manutenção e P\&D) em conjunto, visando uma maior robustez e fidedignidade na estimativa dos parâmetros de forma a representar a mensuração da relação de causa e efeito entre esses investimentos e o custo de Mão de obra se mostraram não conclusivos devido ao reduzido número de graus de liberdade possíveis na amostra. Por sua vez, ocasionando a necessidade de redução do número de defasagens consideradas, o que interferiu significativamente nos resultados obtidos. Sugere-se, a partir desta constatação, o desenvolvimento de trabalhos futuros que possam reafirmar a relação de causa e efeito aqui verificada entre esses dois tipos de investimentos. 


\title{
Maintenance and r\&d investments how elements of reduction production costs - one simulated study
}

\begin{abstract}
This study analyzes an experience in simulated environment of the industrial type, the simulated exercise period is equivalent to 10 (ten) rounds or quarterly periods of decisions between 5 (five) competing companies operating within a closed market (oligopoly). Anyway, the set of decisions of each of the companies is analyzed on the perspective of the administration of production costs, in particular, the effect of the amounts of investments in maintenance of the equipment/machines and R\&D in the reduction of costs with labor force. The methodology used is predominantly quantitative, where the measurement of the presumably existing relationship between investments in maintenance of equipment and machines consorted with R\&D investments is estimated, using the data set of managerial decisions through a panel econometric analysis with fixed effects. The results suggest that Maintenance investments, ceteris-paribus, were shown to be more persistent, more intensive than R\&D investments for the analyzed sample.
\end{abstract}

KEYWORDS: Maintenance. R\&D. Simulated Environment. Labor Force. Production Cost. 


\section{REFERÊNCIAS}

ABRAMAN (Associação Brasileira de Manutenção e Gestão de Ativos). Disponível em: <http://www.abraman.org.br/>. Acesso em: 15 jun. 2015.

ABRAMAN (Associação Brasileira de Manutenção e Gestão de Ativos). Disponível em <http://www.abraman.org.br/>. Acesso em 22 de agosto de 2016.

ANDREASSI, T. Estudo das relações entre indicadores de P\&D e indicadores de resultado empresarial em empresas brasileiras. 1999. 213 p. Tese de Doutorado em Administração de Empresas, Universidade de São Paulo - USP, São Paulo, 1999.

ANDREASSI, T.; SBRAGIA, R. Relações entre indicadores de P\&D e de resultado empresarial. Revista de Administração, São Paulo v.37, n.1, p.72-84, janeiro/março 2002.

BELHOT, R. V.; CAMPOS, F. C. Relações entre manutenção e engenharia de produção: uma reflexão. v. 5. São Paulo: Enegep, p.125-34, nov. 1995.

BELMONTE, D. L.; SCANDELARI, L. Gestão do Conhecimento: aplicabilidade prática na gestão da Manutenção. In: ENEGEP: XXVI Encontro Nacional de Engenharia da Produção, Fortaleza - CE, 2006.

CALMANOVICl, C. E. A inovação, a competitividade e a projeção mundial das empresas brasileiras. Revista USP, v.89, p. 190-203, 2011. crossref

CAMPOS, I. M.; VALADARES, E. C. Inovação Tecnologia e Desenvolvimento Econômico. Unpublished paper, v. 6, n. 4, p. 573-610, 1991.

CHANEY, P. K. et al. The impact of new product introductions on the Market value of firms. The Journal of Business, v. 64, 1991.

CHIU, H. N.; HUANG, B. S. The economic design of $x$ control charts under a preventive maintenance policy. International Journal of Quality \& Reliability Management, Cambridge, v. 13, n. 1, p. 61-71, 1996. crossref

CHOLASUKE, C.; BHARDWA, R.; ANTONY, J. The status of maintenance management in UK manufacturing organizations: results from a pilot survey. Journal of Quality in Maintenance Engineering, v. 10, n. 1, p. 5-15, 2004. crossref 
CHRISTENSEN, J. F. Corporate strategy and the management of innovation and technology. Industrial and Corporate Change, v. 11, n. 2, p. 263-288, 2002. crossref

GOEL, R. K. On contracting for uncertain R\&D. Managerial and Decision Economics, v. 20, n. 2, p. 99, mar. 1999. crossref

HALL, B. H. The relationship between firm size and firm grouwth in the US manufacturing sector. The Journal of Industrial Economics, v. 35, n. 4, p. 583$606,1987$. crossref

HULTEN, C. R. Total factor productivity: a short biography. New developments in productivity analysis, University of Chicago Press, p.1-54, 2001. crossref

JONSSON, P. The status of maintenance management in Swedish manufacturing firms. Journal of Quality in Maintenance Engineering, v. 3, n. 4, p. 233-58, 1997. crossref

LAKATOS, E. M.; MARCONI, M. D. A. Técnicas de pesquisa: planejamento e execução de pesquisa, amostragens e técnicas de pesquisa, elaboração, análise e interpretação de dados. 23ed. São Paulo: Atlas, 1996.

LANGLOIS, R. N. The vanishing hand: the changing dynamics of industrial capitalism. Industrial and Corporate Change, v.12, n.2, p.351-885, 2003. crossref

MIRSHAWKA, V. Manutenção Preditiva: Caminho para Zero Defeitos, São Paulo: Makron Books, McGraw-Hill, 1991.

MORRISON, S. Outsourcing growth keeps prognosis upbeat. Chemical Week, New York, v. 164, n. 8; p. 74, fev. 2002.

MORT, J. Nature, value and pursuit of reliable corporate knowledge. Journal of Knowledge Management, v.5, n.3, p. 222-230, 2001. crossref

MURTY, A.S.R.; NAIKAN, V.N.A. Availability and maintenance cost optimization of a production plant. International Journal of Quality \& Reliability Management, Cambridge, v. 12, n. 2, p. 28-35, 1995. crossref

OTANI, M.; MACHADO, W. V. A Proposta de Desenvolvimento da Gestão de Manutenção Industrial na Busca da Excelência ou Classe Mundial. UTFPR. Revista Gestão Industrial. Ponta Grossa (PR), v. 04, n. 02, p. 01-16, 2008. 
QUEIROZ, S. Obstáculos ao investimento em P\&D de empresas estrangeiras no Brasil. Revista USP, v. 89, p. 244-255, 2011. crossref

SENNET, Richard. A corrosão do caráter: as consequências pessoais do trabalho no novo capitalismo. Rio de Janeiro: Record, 2009.

SOURIS, J. P. Manutenção Industrial: custo ou benefício. Lisboa: Lidel, 1992.

WILLIAMSON, O. E. Economics and organization: a primer. California Management Review, v.38, n.2, p.131-146, 1996. crossref

XAVIER, J. Manutenção: Tipos e Tendências. Disponível em: $<$ http://engeman.com.br/site/ptp/artigostecnicos.asp/manutencaotiposetenden cias>, 2005. Acesso em 10 de julho de 2015.

BERTO, A. M.; DIAS JUNIOR, C. M.; CESCONETO, S. M.; SOUZA, G.P. Manutenção e Pesquisa e Desenvolvimento (P\&D) como elementos de redução dos custos de produção - um estudo simulado. $\mathbf{R}$. Gest. Industr., Ponta Grossa, v. 14, n. 1, p. 234-248, jan./mar. 2018. Disponível em: <https://periodicos.utfpr.edu.br/rgi>. Acesso em: XXX.

Correspondência:

Gueibi Peres Souza

Campus Universitário Reitor João David Ferreira Lima, Trindade, Florianópolis, Santa Catarina, Brasil. Direito autoral: Este artigo está licenciado sob os termos da Licença Creative Commons-Atribuição 4.0 Internacional.

\section{(c) (1)}

